\title{
The Launch of Studies in Learning and Teaching (SiLeT)
}

\author{
N Suprapto' ${ }^{1}$ B K Prahani ${ }^{2 *}$, M N S Abdullah' ${ }^{3}$, T-H Cheng4 \\ 1,2Universitas Negeri Surabaya, Surabaya 60231, Indonesia \\ 3University of Malaya, Kuala Lumpur 50603, Malaysia \\ ${ }^{4}$ National Dong Hwa University, Hualien 97401, Taiwan
}

\section{Article Info}

Article history:

Received March 31, 2020

Revised April 6, 2020

Accepted April 7, 2020

\section{Keywords:}

Journal

SiLeT

Learning

Teaching

\begin{abstract}
This short paper introduces 'Studies in Learning and Teaching' (SiLeT) as a new journal. As an international peer-reviewed journal, SiLeT aware of the quality of the content. The rational, the purpose, and the scope are illustrated as the opening speech of the journal. Since the number of learning and teaching journals is still lacking in accommodating the ideas of researchers and scholars in the world especially in the domain of education, therefore, the existence of SiLeT will fill the void of scientific discussion, especially in terms of "learning, teaching, curriculum development, learning environments, teacher education, educational technology, educational developments, measurement and evaluation, educational statistics, books review of education and other learning-teaching issues".
\end{abstract}

\section{RATIONALE}

Having experience in developing a new journal called 'Studies in Philosophy of Science and Education - SiPoSE' (Suprapto, Ku, Cheng, \& Prahani, 2020), we extend our dedication to the academic field. We, therefore launch a new journal in the learning and teaching domain, 'Studies in Learning and Teaching - SiLeT'. This new journal will aim to advance and disseminate scientific research and discovery, "to publish high-quality studies in the areas of learning, teaching, curriculum development, learning environments, teacher education, educational technology, educational developments, measurement and evaluation, educational statistics, and other learning-teaching issues" (scie-journal.com).

As Terheggen (2012) underlined, "every time a new journal is launched, we work hard to ensure it is a well-considered, and hopefully balanced, solution that meets the community's needs". By following his tips in developing and launching a new journal, there are some considerations: (1) we deliberate whether this journal provides a perfect infrastructure for new topics. We need to look outside the box, and make sure whether the topic is of interest and fulfill the demand of the established community. We deliberate a wide range of factors, including the discussions with reader, our guess editors, other scholars, and other researchers. Additionally, we should also consider the marketing process of the journal; highlight new topics and key words; and a smart study of citation analysis and citation maps. (2) We've taken the judgment that a new journal is required and the time is suitable so what happens next? (Terheggen, 2012).

Moreover, Davidson (2008) offered some suggestions when launching a new journal:

- "A new journal needs an active academic constituency which is large enough to supply a sustained flow of publishable articles".

- "A new journal should consider the community behind it". Many new journals resulted when the community should be growing robustly or undergoing fundamental change. If a subject is in steady state, researchers are likely to continue publishing their quality papers in the same journals they always have. 
- “A new journal needs a vigorous, well networked Editor to draw the community together around the new title". For example, this journal is established due to the effort of some scholars from Indonesia, Malaysia, Taiwan, Japan, and Australia. In the following year, the contribution of other scholars around the world is engaged.

"If these elements are in place and all are essential then a series of 'multipliers' can help the new title flourish even more" (Davidson, 2008).

Currently, there are thirty (30) journals and proceedings based on the Scimagojr with keywords 'learning and teaching', i.e. "New Direction for Teaching and Learning"- WileyBlackwell, "Innovation in Language Learning and Teaching"- Taylor \& Francis, "AsiaPacific Forum on Science Learning and Teaching"- Hong Kong Institute of Education, "Psychology Learning and Teaching"- SAGE Publications Inc., "Citizenship Teaching and Learning"- Intellect Publishers, etc. (Scimagojr, 2020). This number is still lacking in accommodating the needs of exploring learning and teaching. The existence of Studies in Learning and Teaching (SiLeT) will fill the void of scientific discussion, especially in terms of "learning, teaching, curriculum development, learning environments, teacher education, educational technology, educational developments, measurement and evaluation, educational statistics, books review of education, and other learning-teaching issues" (sciejournal.com). It is noted that SiLeT may relate to any age level - from infants to adults.

Further details of submission procedures are posted on the journal website (https://scie-journal.com/index.php/SiLeT/about). The editors welcome enquiries and suggestions from potential authors on nadisuprapto@unesa.ac.id and nadisuprapto@sciejournal.com.

\section{REFERENCES}

Davidson, B. (2008). Launching a new journal with Routledge and Taylor \& Francis. Editors' Bulletin, 4(3), 93-95.

scie-journal.com. (2020). Studies in Learning and Teaching (SiLeT). Retrieved from https://scie-journal.com/index.php/SiLeT.

Scimagojr. (2020). Lists journal in Learning and Teaching. Retrieved March 30, 2020, fromhttps://www.scimagojr.com/journalsearch.php?q=learning+and+teaching.

Suprapto, N., Ku, C.-H., Cheng, T.-H., \& Prahani, B.K. (2020). Editorial: The launch of Studies in Philosophy of Science and Education (SiPoSE). Studies in Philosophy of Science and Education, 1(1), 1-3. Retrieved from https://sciejournal.com/index.php/SiPoSE/article/view/3.

Terheggen, P. (2012). Deciding to launch a new journal: Some factors we consider when deciding to add a new title to the Elsevier collection. Retrieved March 15, 2020, from https://www.elsevier.com/editors-update/story/publishing-trends/deciding-tolaunch-a-new-journal. 